\title{
Anticancer natural products from Aspergillus neoniger, an endophyte of Ficus carica
}

\author{
Randa Abdou ${ }^{1 *} \mathbb{B}$, Alaa M. Alqahtani ${ }^{2}$ and Gouda H. Attia ${ }^{3}$
}

\begin{abstract}
Background: Several plants have not been investigated for their endophytes, such as the medicinal plant Ficus carica for which anticancer activity has been confirmed. The endophyte Aspergillus neoniger was selected for investigation of its metabolites since it exerted anticancer activities in preliminary screening assays.

Results: Bioactivity-guided chromatographic fractionation was performed on the endophytic extract and resulted in the identification of asperazine and asperazine A through spectroscopic analysis. Moderate cytotoxicity against HeLa cell lines $\left(\mathrm{CC}_{50}=18.4 \mathrm{\mu g} \mathrm{mL}^{-1}\right)$ and moderate antiproliferative effects against HUVEC and $\mathrm{K}-562$ cell lines $(\mathrm{G})_{50}=31.5$ and $24.8 \mathrm{\mu g} \mathrm{mL}^{-1}$, respectively) were observed for asperazine. Asperazine $A$ on the other hand showed weak cytotoxic activity against HeLa cell lines $\left(\mathrm{CC}_{50}=34.6 \mu \mathrm{g} \mathrm{mL}^{-1}\right)$ as well as weak cytostatic activities against HUVEC and $\mathrm{K}-562$ cell lines $(\mathrm{Gl})_{50}=40.7$ and $50.2 \mathrm{\mu g} \mathrm{mL}^{-1}$, respectively) while no antimicrobial activity was detected for both compounds.
\end{abstract}

Conclusions: These results suggest contribution of $A$. neoniger to the reported anticancer activity of the host plant and provides a new source of anticancer metabolites with therapeutic potential.

Keywords: Asperazine, Asperazine A, Aspergillus neoniger, Ficus carica, Endophyte

\section{Background}

Fungi play several important ecological roles. As parasites and pathogens, they often attack many organisms such as animals, humans, plants, and even other fungi. As saprotrophic fungi they play a vital role in the cycling of nutrients (Verma et al. 2009). Endophytes are defined as microorganisms inhabiting plant tissues without causing any diseases (Tan and Zou 2001) and provide an important source of biologically active natural products (Berdy 2005) many of which represent promising sources of anticancer drugs (Aly et al. 2008). It has been recommended to choose a plant exerting biological activities and growing in special environments for the study of its endophytes (Strobel 2006). Therefore, Ficus carica for which a wide range of biological activities has been

\footnotetext{
*Correspondence: rfabdou@uqu.edu.sa

${ }^{1}$ Department of Pharmacognosy, Faculty of Pharmacy, Umm Al-Qura

University, Makkah, Kingdom of Saudi Arabia

Full list of author information is available at the end of the article
}

reported was chosen to explore its endophytes. In folk medicine, this plant was found to improve several disorders such as cardiovascular, gastrointestinal, respiratory disorders and ulcerative diseases (Vieira and Kijjoa 2005). It was employed in folk medicine as an antibacterial, antidiabetic and hypotensive agent. The extract of Ficus carica was reported to exert cancer suppressive and antiviral effects (Herre et al. 2008; Joseph and Raj 2011). A recent study on endophytes of $F$. carica growing in India examined their possible administration as biocontrol agents (Rosli et al. 2020; Kour 2020). Antimicrobial activity against several bacterial strains was reported for Ficus carica extract $(\mathrm{MIC}=0.313-5 \mathrm{mg} / \mathrm{mL}$ ) (Joeng et al. 2009) as well as antifungal effects against C. albicans (MIC $=500 \mu \mathrm{g} / \mathrm{mL}$ ) and Microsporum canis (MIC $=75 \mu \mathrm{g} / \mathrm{mL}$ ) (Aref 2010). Furthermore, antitumor activity was also confirmed against Huh7it liver cancer cells for the plant extract $\left(\mathrm{IC}_{50} \mathrm{f}>653 \mu \mathrm{g} / \mathrm{mL}\right.$ ) (Purnamasari 2019a, b). Taking the reported activities of the plant and the tropical growth conditions in Makkah, 
Saudi Arabia in consideration, F. carica was chosen for investigation of its endophytes. We investigated whether its bioactive endophyte $A$. neoniger contributes to the plant's reported antimicrobial and anticancer activities. Aspergillus is considered as a rich source of natural products (Samson 2014; Matsunaga 2021) with a wide range of biological effects (Inglis et al. 2013). Several compounds with useful medicinal effects were obtained from it such as geldanamycin which acts as an antitumoral agent, plakortide which exhibits antiparasitic action, spinosyn which exerts insecticidal effects and lovastatin which reduces cholesterol levels (Sanchez 2012; Bok 2009; Benny 2008).

\section{Methods}

\section{Collection of the plant and isolation of the endophyte}

Plant collection was carried out from Wadi Fatima, Makkah, Saudi Arabia and Dr. Hany Gouda conducted its identification. The plant was kept as a voucher specimen (UQU-2019-1) at the herbarium of the Faculty of Pharmacy, Umm Al-Qura University. The plant material was first cut into small pieces, sterilized, and dried under a laminar flow hood. Outer tissues were removed, and inner tissues dissected and planted onto malt agar (MA) plates containing $0.1 \mathrm{~g}$ streptomycin as an antibiotic. Plates were incubated at room temperature for one month followed by bringing hyphal tips into fresh malt agar medium. Duplicate plates were prepared to eliminate the possibility of contamination and repeated inoculation was carried out to isolate the pure strain. Chloramphenicol $(0.2 \mathrm{~g})$ or streptomycin or $(0.1 \mathrm{~g})$ were added to inhibit bacterial growth during fungal isolation (Zhang et al. 2006).

\section{Identification of the fungal strain}

By using the standard protocol based on the cultural and microscopical properties of the isolated fungal strain its identification was performed (Barnett and Hunter 1998) and was re-confirmed by the Microloge system (Biolog, Inc., Hayward, CA) at the National Research Central Lab., GSFMO, Saudi Arabia (Grizzle and Zak 2006).

\section{Fermentation, extraction and fractionation of the endophyte}

The isolated fungus was cultivated for two weeks on potato dextrose agar (PDA) at $23{ }^{\circ} \mathrm{C}$. The mycelium of each plate was used to inoculate a $1 \mathrm{~L}$ Erlenmeyer flask containing $250 \mathrm{~mL}$ of the MPG-medium which consisted of soybean flour $(2 \mathrm{~g} / \mathrm{L})$, glucose $(10 \mathrm{~g} / \mathrm{L})$, yeast extract $(1 \mathrm{~g} / \mathrm{L})$, malt extract $(20 \mathrm{~g} / \mathrm{L}), \mathrm{KH}_{2} \mathrm{PO}_{4}(1 \mathrm{~g} / \mathrm{L})$ and $\mathrm{MgSO}_{4} .7 \mathrm{H}_{2} \mathrm{O}(0.5 \mathrm{~g} / \mathrm{L})$. A $60 \mathrm{~L}$ stationary culture was incubation for three weeks $\left(23{ }^{\circ} \mathrm{C}\right)$ under static conditions. Afterwards, the culture filtrate and mycelium were homogenized, then macerated for $24 \mathrm{~h}$ in $200 \mathrm{~mL}$ ethyl acetate and finally decanted. The extract obtained was evaporated to dryness and defatted with $n$-hexane. Fractionation of the defatted extract was performed on Silica gel using chloroform and methanol (9:1), followed by fractionation on Sephadex LH-20 using methanol as an eluent and finally purifying the bioactive natural products using preparative HPLC by elution with $25 \%$ acetonitrile in $\mathrm{H}_{2} \mathrm{O}$. This resulted in the isolation of asperazine $(5 \mathrm{mg})$ and asperazine $\mathrm{A}(5.5 \mathrm{mg})$.

\section{Antimicrobial screening}

The agar diffusion test was performed according to the National committee for clinical laboratory standards (NCCLS) guidelines (Wayne 2002; Afonin 2003) to examine the antimicrobial activity.

\section{Anticancer assay}

Human immortal cervical cancer cells (HeLa), Human umbilical vein endothelial cells (HUVEC) and human immortalized myelogenous leukemia cells (K-562) were cultured in Roswell Park Memorial Institute medium (RPMI 1640), Dulbecco's Modified Eagle's Medium (DMEM) and RPMI 1640 medium, respectively. The cell culture medium was provided with $500 \mu \mathrm{L} \mathrm{L}^{-1}$ gentamicin sulfate, $10 \mathrm{~mL} \mathrm{~L}^{-1}$ ultraglutamine 1 and $10 \%$ heat-inactivated fetal bovine serum at $37{ }^{\circ} \mathrm{C}$ in highdensity polyethylene flasks. The anticancer assay was performed and evaluated as previously described in the literature (Abdou 2010; Macabeo 2013). The concentration for $50 \%$ of maximal inhibition of cell proliferation $\left(\mathrm{GI}_{50}\right)$ and the $50 \%$ cytotoxic concentration $\left(\mathrm{CC}_{50}\right)$ of the investigated samples were calculated by determining the intersection of the dose response curve with the $50 \%$ line, compared to untreated control. The obtained values were compared using Magellan software (TECAN).

\section{Results}

Isolation of bioactive endophytic secondary metabolites

The extract of the strain cultivated in MPG medium showed potent cytotoxic effects against HeLa $\left(C_{50}=6.2 \mu \mathrm{g} \mathrm{mL}^{-1}\right)$ in addition to antiproliferative effects against $\mathrm{K}-562$ and HUVEC cell lines $\left(\mathrm{GI}_{50}=5.9\right.$ and $4.8 \mu \mathrm{g} \mathrm{mL}^{-1}$ respectively). Column chromatographic fractionation of the defatted methanolic extract started on Silica gel using chloroform and methanol (9:1) as a solvent mixture followed by gradual increase of polarity till elution with $100 \%$ methanol. Fractions of similar chromatographic properties were combined, and final fractions obtained were assayed for anticancer activity. Active fractions were purified using Sephadex LH-20. Final purification was performed on preparative column 
chromatography using $25 \%$ acetonitrile in water on reversed phase silica as a stationary phase.

\section{Structure elucidation of bioactive metabolites}

The first secondary metabolite obtained appeared as white powder and a molecular formula of $\mathrm{C}_{40} \mathrm{H}_{37} \mathrm{~N}_{6} \mathrm{O}_{4}$ has been indicated for it by HRESIMS and a molecular weight of $m / z 665.3190[\mathrm{M}+\mathrm{H}]^{+}$calcd, 665.3193. The ${ }^{1} \mathrm{H}$ NMR spectrum revealed the presence of five aromatic proton signals corresponding to protons $\mathrm{H}-19-\mathrm{H}-23$ and their aromatic carbons $\mathrm{C}-19-\mathrm{C}-23$ were detected in the ${ }^{13} \mathrm{C}$ NMR and DEPT spectra as well, thus indicating the presence of a substituted aromatic ring. The HMBC spectrum revealed a correlation between the proton at $\delta$ $7.05 \mathrm{ppm}$ and the carbon signal at $\delta 36.6 \mathrm{ppm}$ in addition to a correlation between the proton signal at $\delta 7.1 \mathrm{ppm}$ and the same carbon signal at $\delta 36.7 \mathrm{ppm}$ thus confirming connection of this aromatic ring to a methylene group at $\delta 36.7 \mathrm{ppm}$. Accordingly, the first part of the structure of this natural product was revealed to be a phenyl alanyl group.

Furthermore, four methine carbons of another aromatic ring (C-5-C-8) were in the ${ }^{13} \mathrm{C}$ NMR and DEPT spectra as well as four corresponding aromatic protons ( $\mathrm{H}-5-\mathrm{H}-8)$, thus representing a disubstituted aromatic ring.

HMBC correlations indicated that the substituted carbons of this aromatic ring are the quaternary carbons at $\delta 148.5$ ppm (C-9) and $134.1 \mathrm{ppm}(\mathrm{C}-4)$ which are connected to an olefinic quaternary carbon at $\delta 59.2 \mathrm{ppm}$ (C-3) that is correlated in HMBC with $\mathrm{H}-6$ at $\delta 6.50 \mathrm{ppm}$. The connection of a heteroatom to the quaternary carbon at $\delta 148.5 \mathrm{ppm}(\mathrm{C}-9)$ of this aromatic ring was concluded from its high chemical shift. These NMR data led to the deduction of a tryptophan subunit for the structure of this natural product. The quaternary carbon at $\delta$ $59.2 \mathrm{ppm}(\mathrm{C}-3)$ is correlated with the protons attached to $\mathrm{C}-12(\delta 3.24$ and $2.41 \mathrm{ppm})$ which is itself connected to the aromatic ring moiety containing the aromatic quaternary carbon $(\mathrm{C}-24)$ at $\delta 126.2 \mathrm{ppm}$.

From these correlations, it was concluded that this aromatic ring belonged to a second tryptophan unit of the structure. This was confirmed by HMBC correlations (Fig. 2) observed for $\mathrm{H}-27$ at $\delta 7.51 \mathrm{ppm}$ to the quaternary carbon $\mathrm{C}-32$ at $\delta 108.8 \mathrm{ppm}$, the high chemical shift of C-29 ( $\delta 135.4 \mathrm{ppm})$ supporting its connection to an imine group, as well as the correlation of the methylene protons $\mathrm{H}-33$ at $\delta 3.04$ and $3.08 \mathrm{ppm}$ with $\mathrm{C}-29$ ( $\delta$ $135.4 \mathrm{ppm})$. By comparison of the structure suggested in Fig. 1 for the compound and its NMR data (Additional file 1: Table S1) with literature its identity was confirmed as asperazine, the diketopiperazine dimer previously isolated from $A$. niger obtained from a Caribbean sponge (Varoglu 1997).

Analysis of the NMR data of the second metabolite isolated from $A$. neoniger endophyte revealed it to be a homologue of asperazine (1) with the same molecular weight (HRESIMS, $m / z 665.3190[\mathrm{M}+\mathrm{H}]^{+}$calcd 665.3193) and molecular formula $\left(\mathrm{C}_{40} \mathrm{H}_{37} \mathrm{~N}_{6} \mathrm{O}_{4}\right)$. The main differences between the two metabolites were the observed higher chemical shift of C-3 at $\delta 72.6 \mathrm{ppm}$ indicating its attachment to a nitrogen atom and the lower chemical shift of $\mathrm{C}-24$ at $\delta 111.3 \mathrm{ppm}$. Additionally, the DEPT spectrum revealed $\mathrm{C}-24$ to be a primary carbon, while it is a quaternary carbon in compound $\mathbf{1}$. Accordingly, a connection of the two subunits of the structure elucidated for (1)

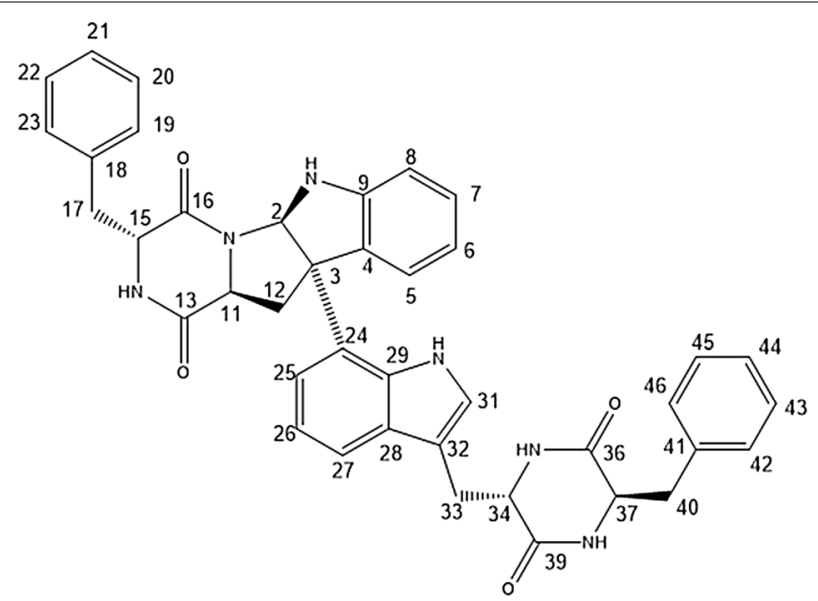

1

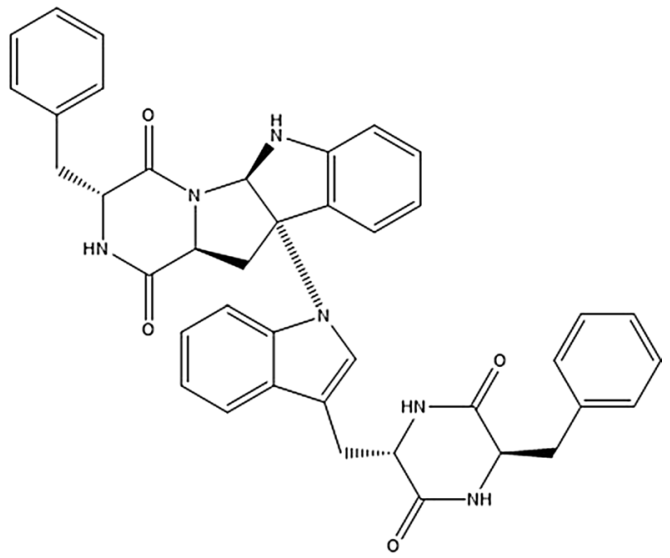

2

Fig. 1 Chemical structures of asperazine (1) and asperazine A (2) 


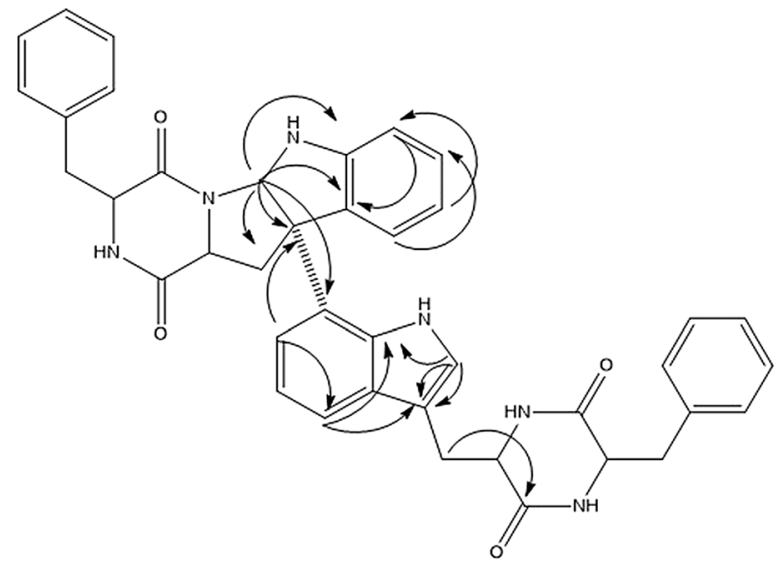

1

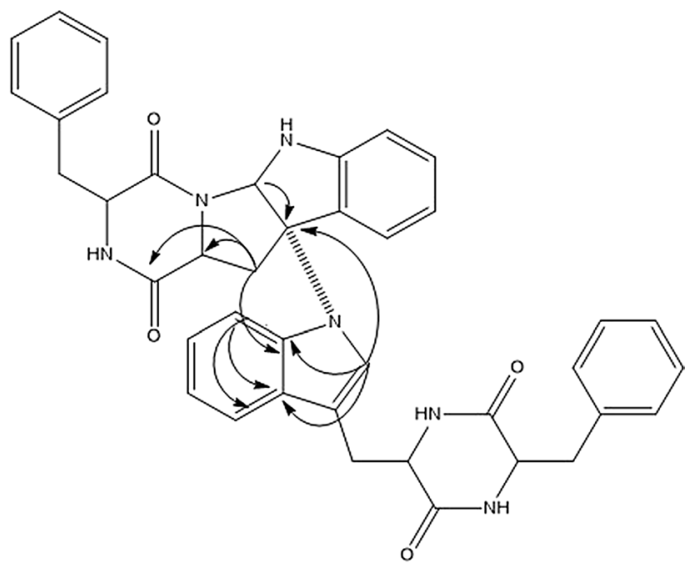

2

Fig. $2 \mathrm{HMBC}$ correlations of asperazine (1) and asperazine A (2)

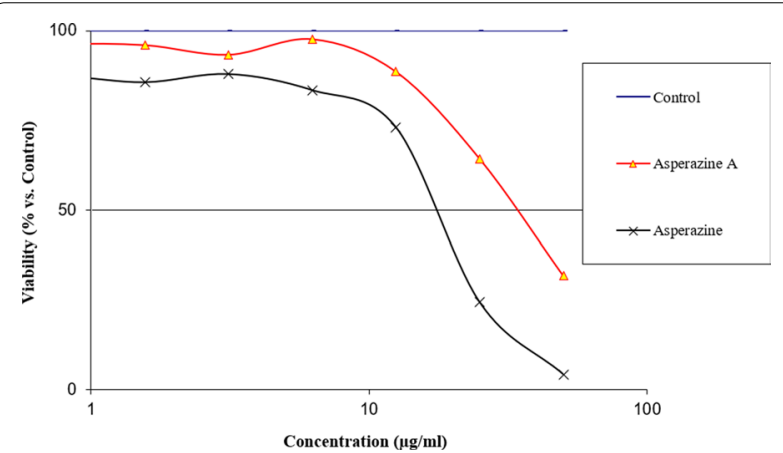

Fig. 3 Cytotoxic activities of asperazine (1) and asperazine A (2) on HeLa

through a $\mathrm{C}-\mathrm{N}$ bond from $\mathrm{C}-3$ to the inolic nitrogen was concluded for the dimer of compound (2). The suggested structure for 2 was confirmed by HMBC correlations (Fig. 2) observed from the methylenic protons $(\mathrm{H}-12)$ to $\mathrm{C}-11, \mathrm{C}-13, \mathrm{C}-28$, and $\mathrm{C}-29$ in addition to correlations observed from $\mathrm{H}-31$ to $\mathrm{C}-3, \mathrm{C}-28$, and $\mathrm{C}-29$. These data led to the deduction of the structure of asperazine A presented in Fig. 3 for this compound which was matching with previously reported literature data of the compound (Lia 2015).

\section{Discussion}

Asperazine was previously isolated from Aspergillus tubingensis as a marine microbial metabolite and was found to exert cytotoxic activity against leukemia cells but showed no antimicrobial action (Ovenden 2004). Our assay revealed moderate cytotoxicity of asperazine against the human immortal cervical cancer cell line (HeLa) (Fig. 3) and moderate cytostatic activity

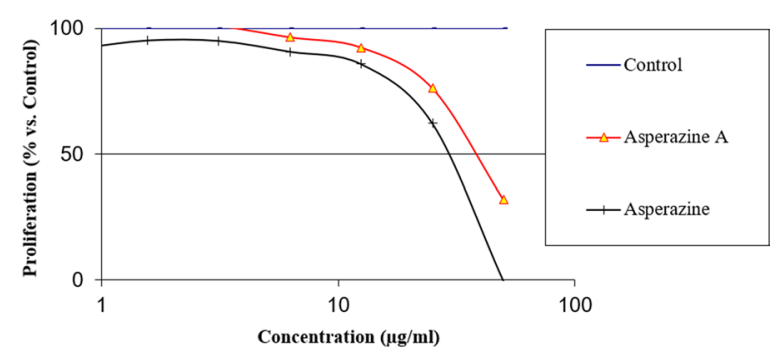

Fig. 4 Antiproliferative effects of asperazine (1) and asperazine A (2) on HUVEC

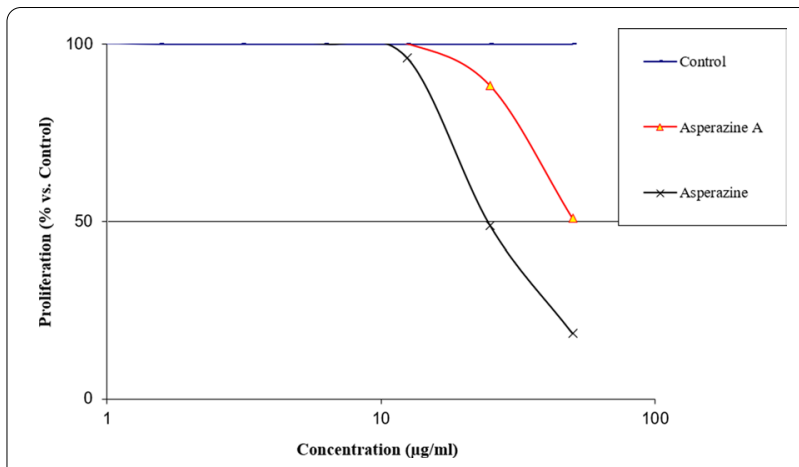

Fig. 5 Antiproliferative effects of asperazine (1) and asperazine A (2) on K-562

against human umbilical vein endothelial cells (HUVEC) and human immortalized myelogenous leukemia cells (K-562). A value of $19.2 \mu \mathrm{g} \mathrm{mL}^{-1}$ was obtained for the $\mathrm{CC}_{50}$ of asperazine against HeLa cell line and $\mathrm{GI}_{50}$ values of 31.4 and $24.6 \mu \mathrm{g} \mathrm{mL} \mathrm{m}^{-1}$ against HUVEC and K-562 cell lines, respectively (Figs. 4, 5). In a reported study 
analysis of extracts of $140 \mathrm{~A}$. niger, $177 \mathrm{~A}$. tubingensis, one $A$. vadensis and 47 Aspergillus acidus strains revealed production of asperazine only by $A$. acidus and $A$. tubingensis (Nielsen 1999). The rather limited biosynthesis of this secondary metabolite by Aspergillus species led to its consideration as a marker for differentiation of severely toxic Aspergillus niger species from the less toxic $A$. acidus and A. tubingensis species (Nielsen 1999).

Asperazine $\mathrm{A}$ also exerted moderate cytotoxic activity against HeLa cell lines by exhibiting a $\mathrm{CC}_{50}$ value of $34.4 \mu \mathrm{g} \mathrm{mL} \mathrm{m}^{-1}$ and weak cytostatic activities against HUVEC and K-562 cell lines with $\mathrm{GI}_{50}$ values of 40.5 and $50 \mu \mathrm{g} \mathrm{mL}^{-1}$ (Figs. 3, 4, 5), while no antimicrobial activity was detected for both compounds in the conducted agar diffusion assay.

Recently, a study reported the detection of asperazine $\mathrm{A}$ in an endophytic $A$. niger strain of the liverwort Heteroscyphus tener. It was found to exert weak cytotoxicity against the cancer cell lines PC3, A2780, K562, MBA-MD-231, and NCI-H1688 (Lia 2015). Since the anticancer activity of asperazine is higher than that of its homologue asperazine $\mathrm{A}$, the connection of the two subunits of this diketopiperazine dimer through the C-N bond from $\mathrm{C}-3$ to the inolic nitrogen seems to reduce its biological activity.

\section{Conclusion}

In conclusion an A. neoniger strain has been isolated from the medicinal plant $F$. carica and tested for anticancer activity in an attempt of finding out if it contributes to the anticancer activity reported for the host plant. Two natural products, asperazine and asperazine A were isolated as bioactive fungal metabolites which supports the assumption that this endophyte contributes to the host plant's anticancer activity. The cytotoxic and antiproliferative effects of asperazine against HeLa, HUVEC, and K-562 are higher than those of asperazine A indicating the importance of the $\mathrm{C}-\mathrm{N}$ bond connecting the two subunits of the diketopiperazine dimer for the biological activity.

\section{Abbreviations}

MIC: Minimum inhibitory concentration; $\mathrm{CC}_{50}$ : Cytotoxic concentration 50; $\mathrm{GI}_{50}$ : Growth inhibition 50\%; HMBC: Heteronuclear multiple bond correlations; NMR: Nuclear magnetic resonance; HUVEC: Human umbilical vein endothelial cell; HRESIMS: High-resolution electrospray ionization mass spectrometry; GSFMO: Grain silos and flour milling organization; MPG-medium: Malt potato glucose medium.

\section{Supplementary Information}

The online version contains supplementary material available at https://doi. org/10.1186/s42269-021-00536-8.

Additional file 1. Supplementary data.

Acknowledgements

The authors would like to thank the Deanship of Scientific Research at Umm Al-Qura University for funding this study through a Grant Coded: 19-MED-1-03-0005.

\section{Authors' contributions}

RA has designed the study, carried out the identification procedures of the secondary metabolites and wrote the manuscript. AA has carried out the extraction and isolation steps. GA has carried out plant identification, collection, and the in vitro activity. All authors have read and approved the manuscript.

\section{Funding}

This work has been fully supported and funded by a Grant code 19-MED-103-0005 from the Deanship of Scientific Research at Umm Al-Qura University which provided all required materials, basic supplies, manpower and analysis.

Availability of data and materials

All data and material are available upon request.

\section{Declarations}

Ethics approval and consent to participate

Not applicable.

Consent for publication

Not applicable.

Competing interests

The authors declare that they have no competing interests.

\section{Author details}

1 Department of Pharmacognosy, Faculty of Pharmacy, Umm Al-Qura University, Makkah, Kingdom of Saudi Arabia. ${ }^{2}$ Department of Pharmaceutical Chemistry, Faculty of Pharmacy, Umm Al-Qura University, Makkah, Kingdom of Saudi Arabia. ${ }^{3}$ Department of Pharmacognosy, College of Pharmacy, Najran University, Najran, Kingdom of Saudi Arabia.

Received: 20 March 2021 Accepted: 4 April 2021

Published online: 13 April 2021

\section{References}

Abdou R et al (2010) Botryorhodines A-D, antifungal and cytotoxic depsidones from Botryosphaeria rhodina, an endophyte of the medicinal plant Bidens pilosa. Phytochemistry 71:110-116

Afonin SR et al (2003) 4-fluorophenylglycine as a label for 19F NMR structure analysis of membrane-associated peptides. Chem Biochem 4:1151-1163

Aly AH et al (2008) Cytotoxic metabolites from the fungal endophyte Alternaria sp. and their subsequent detection in its host plant Polygonum senegalense. J Nat Prod 71:972-980

Aref HL et al (2010) In vitro antimicrobial activity of four Ficus carica latex fractions against resistant human pathogens (antimicrobial activity of Ficus carica latex). Pak J Pharm Sci 23:53-58 
Barnett HL, Hunter BB (1998) Illustrated genera of imperfect fungi. APS Press, St. Paul

Benny O et al (2008) An orally delivered small-molecule formulation with antiangiogenic and anticancer activity. Nat Biotechnol 26:799-807

Berdy J (2005) Bioactive microbial metabolites. J Antibiot (Tokyo) 58:1-26

Bok JW et al (2009) Chromatin-level regulation of biosynthetic gene clusters. Nat Chem Biol 5:462-464

Grizzle HW, Zak JC (2006) A microtiter plate procedure for evaluating fungal functional diversity on nitrogen substrates. Mycologia 98:353-363

Herre EA, Jander C, Machado CA (2008) Evolutionary ecology of figs and their associates: recent progress and outstanding puzzles annu. Rev Ecol Evol Syst 39:439-458

Inglis DO et al (2013) Comprehensive annotation of secondary metabolite biosynthetic genes and gene clusters of Aspergillus nidulans, A. fumigatus, A. niger and A. oryzae. BMC Microbiol 13:91

Joeng MR, Kim HY, Cha JD (2009) Antimicrobial activity of methanol extract from Ficus carica leaves against oral bacteria. J Bacteriol Virol 39:97-102

Joseph B, Raj SJ (2011) Pharmacognostic and phytochemical properties of Ficus carica Linn: an overview. Int J Pharmtech Res 3:08-12

Kour $\mathrm{D}$ et al. Endophytic fungi from medicinal plants: biodiversity and biotechnological applications. In: Microbial endophytes; 2020. p. 273-305.

Lia X-B et al (2015) A new diketopiperazine heterodimer from an endophytic fungus Aspergillus niger. J Asian Nat Prod Res 17:182-187

Macabeo APG et al (2013) Antitubercular and cytotoxic constituents from Goniothalamus gitingensis. Rec Nat Prod 8:41-45

Matsunaga E et al (2021) Identification and characterization of beta-d-galactofuranosidases from Aspergillus nidulans and Aspergillus fumigatus. J Biosci Bioeng 131:1-7

Nielsen KF et al (1999) Production of mycotoxins on artificially and naturally infested building materials. Mycopathologia 145:43-56

Ovenden SP et al (2004) A diketopiperazine dimer from a marine-derived isolate of Aspergillus niger. J Nat Prod 67:2093-2095

Purnamasari R et al (2019a) Anticancer activity of methanol extract of Ficus carica leaves and fruits against proliferation, apoptosis and necrosis in Huh7it cells. Cancer Inform 18:1-7
Purnamasari R et al (2019b) Anticancer activity of methanol extract of Ficus carica leaves and fruits against proliferation, apoptosis, and necrosis in Huh7it cells. Cancer Inform 18:1176935119842576

Rosli NM, Ashari KIAH, Azmi NSA (2020) Isolation and preliminary screening of endophytic fungi from Ficus carica for biocontrol and phosphate solubilization. Environ Ecosyst Sci 4:77-84

Samson RA et al (2014) Phylogeny, identification and nomenclature of the genus Aspergillus. Stud Mycol 78:141-173

Sanchez JF et al (2012) Advances in Aspergillus secondary metabolite research in the post-genomic era. Nat Prod Rep 29:351-371

Strobel G (2006) Harnessing endophytes for industrial microbiology. Curr Opin Microbiol 9:240-244

Tan RX, Zou WX (2001) Endophytes: a rich source of functional metabolites. Nat Prod Rep 18:448-459

Varoglu M et al (1997) Asperazine, a selective cytotoxic alkaloid from a sponge-derived culture of Aspergillus niger. J Org Chem 62:7078-7079

Verma VC, Kharwar RN, Strobel GA (2009) Chemical and functional diversity of natural products from plant associated endophytic fungi. Nat Prod Commun 4:1511-1532

Vieira LM, Kijjoa A (2005) Naturally-occurring xanthones: recent developments. Curr Med Chem 12:2413-2446

Wayne PA. Reference method for broth dilution susceptibility testing of filamentous fungi. Approved Standard. M38-A, USA, NCCls. 2002.

Zhang HW, Song YC, Tan RX (2006) Biology and chemistry of endophytes. Nat Prod Rep 23:753-771

\section{Publisher's Note}

Springer Nature remains neutral with regard to jurisdictional claims in published maps and institutional affiliations.

\section{Submit your manuscript to a SpringerOpen ${ }^{\circ}$ journal and benefit from:}

- Convenient online submission

- Rigorous peer review

- Open access: articles freely available online

- High visibility within the field

- Retaining the copyright to your article

Submit your next manuscript at $\boldsymbol{\nabla}$ springeropen.com 